\title{
HIGH-FREQUENCY ACTUATION WITH SILICON ELECTROOSMOTIC MICROPUMPS
}

\author{
Daniel J. Laser, Kenneth E. Goodson, Juan G. Santiago, and Thomas W. Kenny \\ Department of Mechanical Engineering, Stanford University \\ Stanford, California 94305
}

\begin{abstract}
Electroosmotic micropumps manufactured on silicon substrates using standard micromachining processes can generate pressures of $6 \mathrm{kPa}$ and flow rates of $13 \mu \mathrm{L} / \mathrm{min}$ at $400 \mathrm{~V}$. We present a novel micromachined silicon electroosmotic micropump structure that dramatically reduces die size requirements. We have investigated the prospects for using electroosmotic micropumps in microscale fluidic actuation by integrating a silicon membrane structure into the pump system. By monitoring the velocity of the membrane using a laser vibrometer, we have characterized the micropump's pressure response on timescales below 100 milliseconds. The silicon electrosmotic micropumps studied are found to have a finite pressure response within $10 \mathrm{~ms}$ of power activation. Maximum pressure generation, however, appears to take place on a much longer timescale.
\end{abstract}

\section{INTRODUCTION}

Low-voltage electroosmotic micropumps can be fabricated using silicon micromachining in a relatively straightforward manner. The ready integration of micromachined silicon electroosmotic micropumps with other micromachined components makes microactuation a potential application of these micropumps.

Actuator response time is a critical figure of merit for microscale device actuation applications. For micromachined electrostatic comb drive actuators, this response time is generally limited by inertia and is on the order of 1 millisecond or less [1,2]. In contrast, the response time of a fluidic actuator can be limited by a wide range of factors, including the inertia of the fluid, the finite velocity with which a pressure wave propagates through the fluid medium, and, for devices that rely on electric-field-mediated pumps such as electroosmotic pumps, electrochemical effects. In microfluidic actuators, gas bubbles in the fluid and mechanical compliance of fixturing and tubing are a source of volume capacitance that can reduce response time.

To evaluate the usefulness of silicon electroosmotic micropumps for microactuation, we have fabricated very simple microactuators with integrated electroosmotic micropumps. The actuated component is a circular silicon nitride membrane located at the center of an annular electroosmotic micropump, as shown in Figure 1. The design of this device is intended to minimize the impact on response time of finite pressure wave propagation velocity, system volume capacitance, and the membrane's mechanical properties. The system can therefore be used to determine the lower limit on the response time of a microactuator driven by the annular electrosmotic micropump.

\section{ELECTROKINETICS AND ELECTROOSMOTIC FLOW}

Electroosmotic pumps generate fluid flow and pressure through the application of an electrical potential across a stationary, fluid-filled structure (Figure 2). They are among a family of devices that take advantage of the electric double layer that typically forms at a liquid-solid interface [3]. Structures used for electroosmotic pumping must have pore-like features within a few orders of magnitude of the size of the electric double layer, which is generally less than a micron. Electrosmotic pumps made from sintered glass frits have been reported that generate pressures of $250 \mathrm{kPa}$ and flow rates of $7 \mathrm{~mL} / \mathrm{min} \mathrm{[4]}$

\section{SILICON ELECTROOSMOTIC MICROPUMP DESIGN AND PERFORMANCE}

Channels with the micron-scale dimensions appropriate for electroosmotic pumping may be readily fabricated using silicon micromachining, but the silicon substrate limits the electrical potential that can be applied during pump operation to approximately $500 \mathrm{~V}$, even with thin-film insulation [5]. Burgreen and Nakache found that the average velocity of electroosmotic flow generated between two wide parallel surfaces by the application of an axial electric field $E_{x}$ is:

$$
\bar{v}=-\frac{h^{2}}{3 \mu} \frac{d p}{d x}+\frac{\varepsilon \zeta}{\mu} E_{x}[1-G(\alpha, \kappa h)]
$$

where $h$ is one-half the separation distance between the two pumping surfaces, $\mu$ is the fluid viscosity, $d p / d x$ is the pressure gradient counter to the flow, $\varepsilon$ is the fluid permittivity, $\zeta$ is the zeta potential, $\alpha$ is an ionic energy parameter, and $G$ is a correction term for the thickness of the double layer [6]. Electroosmotic pumps made by etching a $5 \mathrm{~cm}$ wide, $1.5 \mu \mathrm{m}$ deep, $500 \mu \mathrm{m}$ long channel in a silicon substrate, coating the substrate with silicon nitride, and sealing with an anodically bonded borosilicate glass cover generate pressures of $2 \mathrm{kPa}$ and flow rates of $5 \mu \mathrm{L} / \mathrm{min}$ at 500 volts $[7,8]$, compared to $150 \mathrm{kPa}$ and $15 \mu \mathrm{L} / \mathrm{min}$ for a glass micropump with a similar design operating at $3 \mathrm{kV}$ [9]. The difference in the performance of these pumps is attributable to the different zeta potentials of silicon nitride and glass as well as to the difference in applied voltage. Both pumps occupy an area of approximately $5 \mathrm{~cm}^{2}$ on the substrate, including the etched channels required to transport fluid to and from the pumping channel.

To improve the flow rate generated by the silicon electroosmotic micropump relative to its size, we plasma etch $3 \mu \mathrm{m}$ wide slots in the silicon substrate to a depth of approximately 100 $\mu \mathrm{m}$. Subsequent conformal deposition of approximately $0.65 \mu \mathrm{m}$ of silicon nitride reduces the slot width to $1.7 \mu \mathrm{m}$. Spacing the slots every $10 \mu \mathrm{m}$ yields a $20 \mathrm{x}$ improvement in flow area per unit substrate surface area over the previous design. By arranging the 360 slots in an annular configuration as shown in Figures 1(a) and (b), we have produced a micropump with a flow area of approximately $7.2 \times 10^{4} \mu \mathrm{m}^{2}$ that fits on a $1 \mathrm{~cm} \times 2 \mathrm{~cm}$ die. Fabrication of the micropump is completed by anodically bonding a Pyrex 7740 wafer to the top side of the silicon wafer by applying 


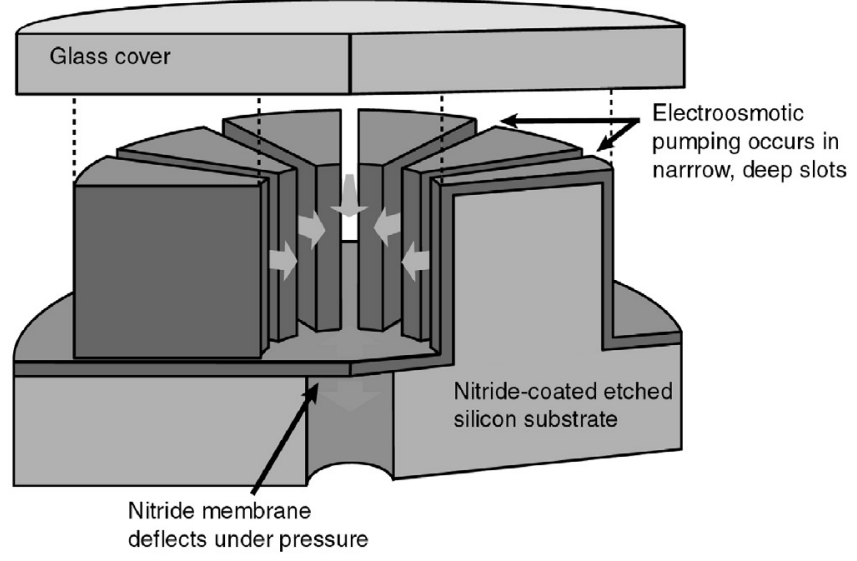

(a)

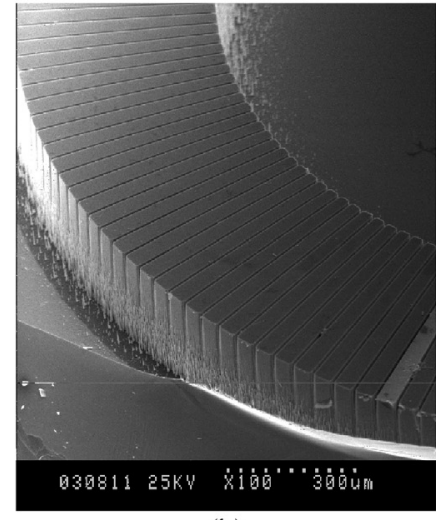

(b)

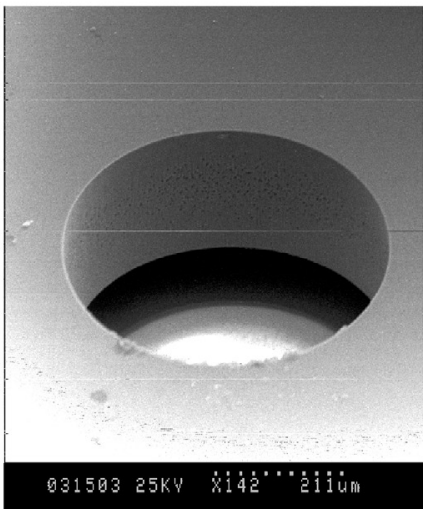

(c)

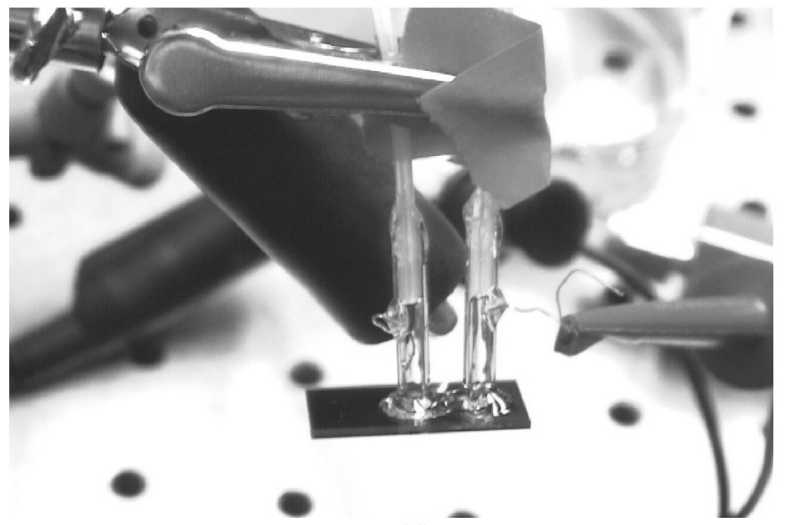

(d)

Figure 1. Structure of microactuator with integrated electoosmotic micropump. (a) Section perspective illustration. The pump structure is defined by a deep-etched circular interior well and a concentric deep-etched annular well. Narrow slots etched radially in the pump structure connect the inner well and the outer annulus. A layer of silicon nitride insulates the surfaces of the inner well, outer annulus, and slots and forms the membrane. (b) Electron micrograph of the top side of the silicon substrate showing a portion of etched annular pump structure. Although the interior well, exterior well, and slots are all etched simultaneously, the slots etch to a lesser depth because of the feature size dependency of the DRIE process. (c) Electron micrograph of the back side of the silicon showing the released circular membrane at the bottom of the etched cavity. (d) Microactuator with external tubing attached for fluid and electrical connections. Holes drilled in the borosilicate glass cover provide access to the interior. The microactuator measures $1 \mathrm{~cm} \times 2 \mathrm{~cm} \times 1 \mathrm{~mm}$.

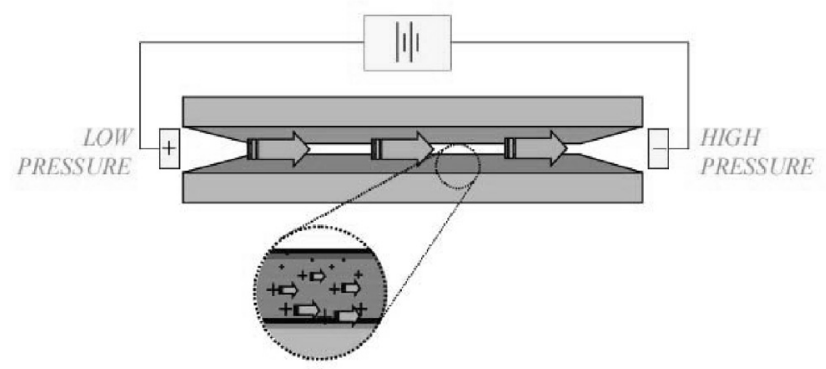

Figure 2. Electroosmotic flow between closely-spaced, flat, parallel surfaces. An externally-applied electric field acts on mobile ions near the surfaces. Viscous interaction generates flow of the bulk liquid.

a potential difference of 1200 volts across the two wafers for 30 minutes at $350^{\circ} \mathrm{C}$. The devices are then diced and access holes drilled in the glass cover using a diamond-tipped drill bit. Fluid and electrical connections are made through $2 \mathrm{~cm}$ glass capillary segments attached to the micropump using UV-cured epoxy. This micropump generates a maximum pressure of $6 \mathrm{kPa}$ and a maximum flow rate of $13 \mu \mathrm{L} / \mathrm{min}$ at $400 \mathrm{~V}$. Power consumption is less than $150 \mathrm{~mW}$. The pressure-flow rate characteristics of the pump, found by measuring compression of room air in a closed capillary, are plotted in Figure 3. The margin of error with this measurement technique is approximately $+/-0.25 \mathrm{kPa}$.

\section{MICROACTUATOR DESIGN, FABRICATION, AND TESTING}

The annular electroosmotic pump described above is converted to an actuator by releasing a circular area of the silicon nitride coating at the center of the interior well using a backside plasma etch, as shown in Figures 1(a) and (c). Devices with membrane diameters of $250 \mu \mathrm{m}$ and $500 \mu \mathrm{m}$ have been fabricated. A 300 angstrom layer of gold with a 50 angstrom chrome adhesion layer is evaporatively deposited on the back side of each die to increase the reflectivity of the nitride membrane. The yield of the

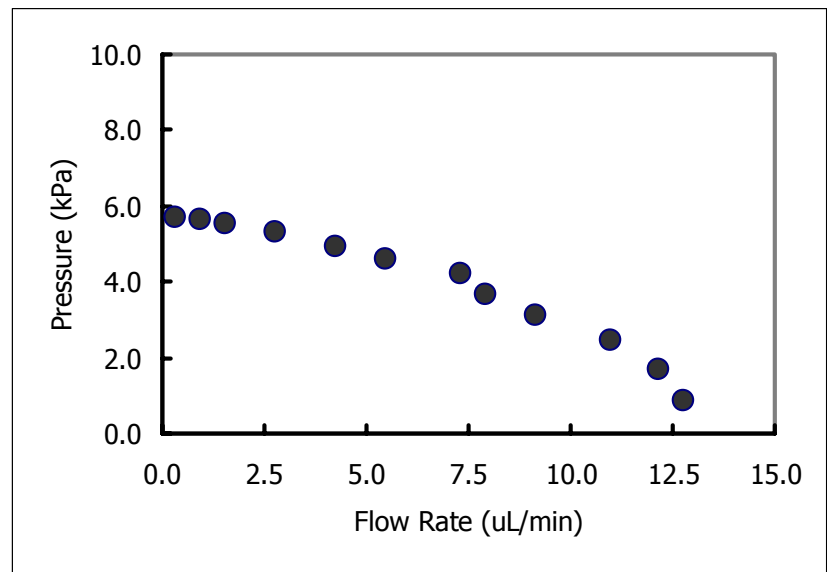

Figure 3. Pressurelflow rate performance of silicon electroosmotic micropump with $3602 \mu \mathrm{m}$ wide slots in an annular configuration. Working fluid is $0.5 \mathrm{mM}$ borate buffer and applied potential is $400 \mathrm{~V}$. 
microactuator fabrication process is approximately $75 \%$, with the lost yield mostly due to exposure issues with thick resist lithography.

The velocity of the membrane during operation is monitored using a laser vibrometer [10]. Pump current is monitored during testing using a series reference resistor. Data is collected using a $1.5 \mathrm{GHz}$ digital oscilloscope. The use of the vibrometer to conduct measurements of membrane velocity-where the membrane is within a millimeter of each of the radially-arrayed pump slots micropump - affords a unique capability for resolving the highspeed temporal response of the microactuator (and, in turn, of the micropump). We found that noise limited the vibrometer's velocity resolution to a few hundred nanometers per second during microactuator testing. A finite element model indicates that applying a $6 \mathrm{kPa}$ differential pressure - the maximum generated by the electroosmotic micropump at $400 \mathrm{~V}$-will result in a steadystate maximum membrane displacement of over $1 \mu \mathrm{m}$ for the 250 $\mu \mathrm{m}$ diameter membrane and over $6 \mu \mathrm{m}$ for the $500 \mu \mathrm{m}$ membrane. In our experience, a portion of the steady-state pressure developed by electroosmotic micropumps arises on a timescale of hundreds of seconds. Such response times are associated with membrane velocities of $10 \mathrm{~nm} / \mathrm{sec}$ or less - velocities below the resolution limit of the vibrometer in our setup. Because of this limitation, the work presented here addresses only the fast $(<100$ millisecond) transient response of the microactuator.

A further limitation on the accuracy of our measurements is imposed by vibrometer laser focusing and alignment issues. The velocity measured by the vibrometer is the average velocity of the region of the membrane illuminated by the laser-a circular area with a diameter of approximately $20 \mu \mathrm{m}$. Using a micrometer stage, we are able to focus the laser within an estimated $25 \mu \mathrm{m}$ of the center of the membrane. The finite spot size of the laser and potential misalignment of the laser with the center of the membrane can be expected to result in underestimation of the membrane maximum displacement by as much as $20 \%$.

\section{EXPERIMENTAL RESULTS AND ANALYSIS}

The microactuators were tested by applying a $400 \mathrm{~V}_{\mathrm{p}-\mathrm{p}}$ sinusoidal input with a $200 \mathrm{~V}$ offset to the pump at frequencies

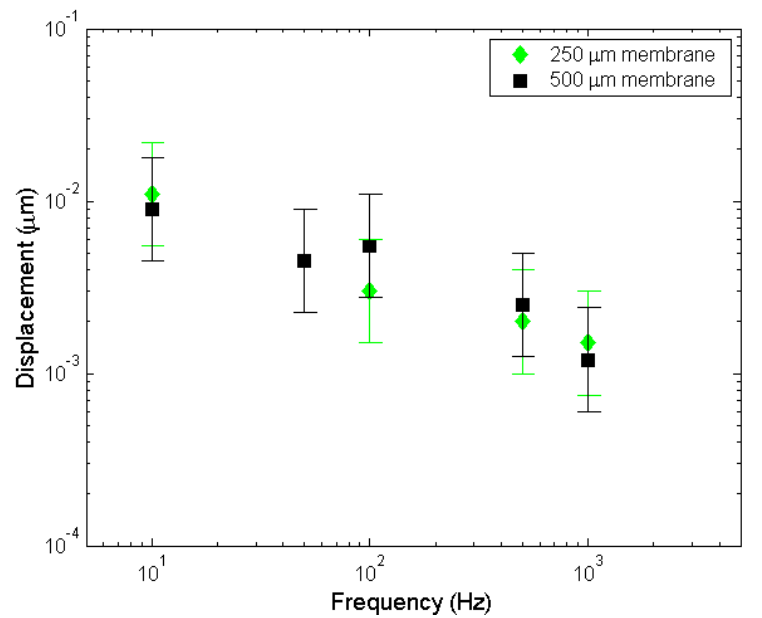

Figure 4. Membrane displacement amplitude for a $400 \mathrm{~V}_{p-p}$ sine wave input (200 V offset) applied to the electroosmotic micropump. Data reflects the average amplitude measured over at least 256 cycles.

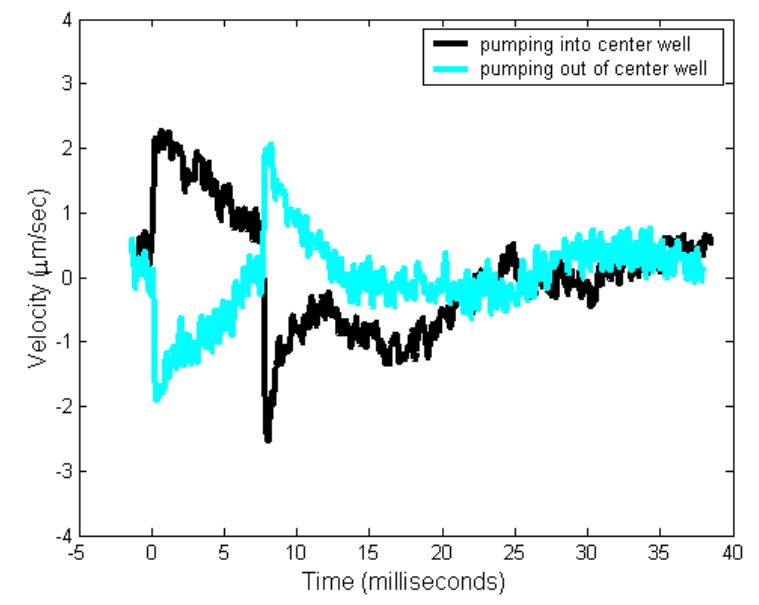

(a)

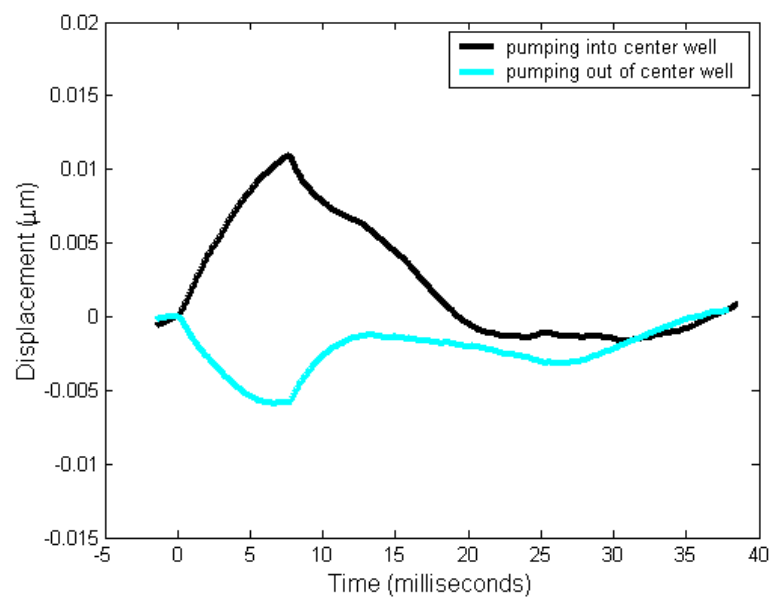

(b)

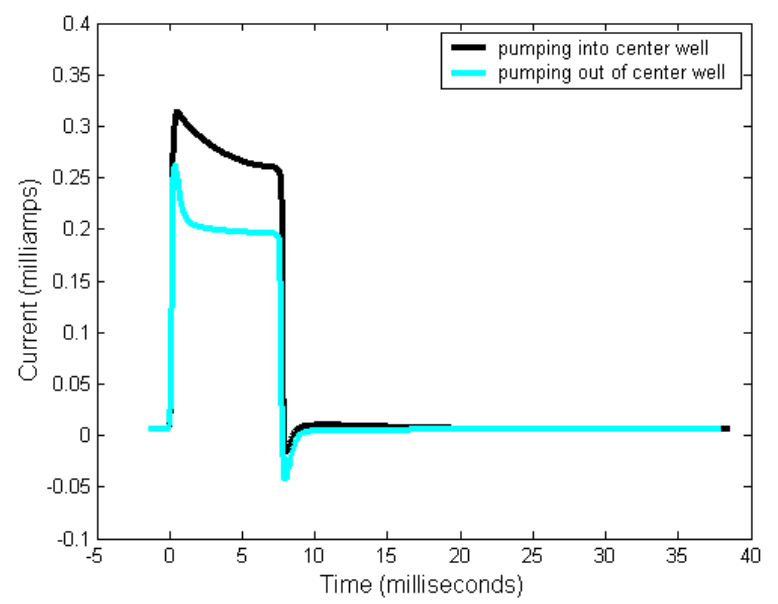

(c)

Figure 5. Bidirectional response of a $500 \mu \mathrm{m}$ microactuator to a $25 \mathrm{~Hz}, 400$ volt square-wave input with a duty cycle of 20\%. Data is averaged over 1,280 cycles. Plots show (a) membrane velocity; (b) membrane displacement (found by integrating velocity), and (c) current through the micropump. Positive velocities and displacements correspond to outward deflection of the membrane. 
ranging from $10 \mathrm{~Hz}$ to $1 \mathrm{kHz}$. At each frequency, data for at least 256 cycles was acquired and averaged to reduce noise in the measurement. Displacement data was calculated by integrating the velocity measured by the vibrometer. The measured velocity represents the average velocity of the portion of the membrane area illuminated by the vibrometer. Membrane displacement amplitude is plotted as a function of frequency in Figure 4.

Figure 5 shows the response of a $500 \mu \mathrm{m}$ diameter actuator to a $25 \mathrm{~Hz}$ square wave input with a $20 \%$ duty cycle at 400 volts. This test was performed for both pumping into the center well (causing the membrane to deflect outward) and out of the center well (causing the membrane to deflect inward). Data was accumulated over 1,280 cycles to reduce noise. The response is qualitatively the same in both directions, although the magnitude of the membrane's outward deflection is larger than its inward deflection.

The measured frequency response and partial step response indicate that electroosmotic microactuators operated closed-loop could be used for applications requiring frequency response into the kilohertz range. The membrane appears to reach only a small fraction of its steady-state displacement in the first eight milliseconds after the voltage is turned on, however, suggesting that the open-loop bandwidth of the device is below $10 \mathrm{~Hz}$. Finite element analysis indicates that the first resonant frequencies of both the $250 \mu \mathrm{m}$ and the $500 \mu \mathrm{m}$ membranes are above $100 \mathrm{kHz}$, so the microactuator response is not believed to be limited by the membrane dynamics. The relatively long timescale apparently required for the pressure generated by the electroosmotic pump to reach its maximum value has been observed in other studies of electroosmotic pumping [11] and is not well understood at this time. Fixturing and tubing leading from the actuator to an external valve may be a source of volume capacitance in the microactuator; as currently designed, the microactuator can not be sealed off directly at the die level because of the need to purge electrolytic gas bubbles between experiments. Gas bubbles in the liquid may also be a source of volume capacitance. Gas bubbles arise not only from electrolysis at the electrodes, but also from degassing (e.g., due to increased temperature which reduces solubility) and, in extreme cases, boiling in or near the pump structure. This may be particularly prominent in zero-net-flow conditions that prevent convective transport of heat out of the pump structure.

\section{CONCLUSIONS}

Micromachined silicon electroosmotic pumps combine the reliability and effectiveness of electroosmotic pumping with the ease of fabrication and ready integration with other micromachined components afforded by silicon micromachining. We have successfully fabricated a simple microactuator driven by an integrated electroosmotic micropump. Tests of the microactuator suggest that electroosmotic micropumps might be suitable for use in applications requiring actuator bandwidth as high as $1 \mathrm{kHz}$, although operation at lower frequencies may be required to produce a quasi-static microactuator response.

\section{REFERENCES}

1. W.C. Tang, T.C.H. Nguyen, and R.T. Howe, "Laterally Driven Polysilicon Resonant Microstructures," Sensors and Actuators, 20, (1989), pp. 25-32.

2. J.D. Grade, H. Jerman, and T.W. Kenny, "A Large-Deflection Electrostatic Actuator for Optical Switching Applications," Technical Digest of the 2000 Solid-State Sensor and Actuator Workshop, Hilton Head Isl., SC, Transducer Research Foundation, Cleveland (1994), pp. 97-100.

3. R. J. Hunter, Zeta Potential in Colloid Science, Academic Press, Inc., San Diego (1981).

4. S. Yao, D.E. Huber, J. Mikkelsen, Jr., and J.G. Santiago, "A Large Flowrate Electrokinetic Pump with Micron Pores," Proceedings of the 2001 ASME International Mechanical Engineering Congress and Exposition, New York, NY, November 11-16, 2001.

5. D. J. Harrison, P. G. Glavina, and A. Manz, "Towards Minitaturized Electrophoresis and Chemical Analysis Systems on Silicon: An Alternative to Chemical Sensors," Sensors and Actuators B, 10 (1993), pp. 107-116.

6. D. Burgreeen and F. R. Nakache, "Electrokinetic Flow in Ultrafine Capillary Slits," J. Phys. Chemistry 68, 5 (1964), pp. 1084-1091.

7. D. Laser, S. Yao, C. Chen, J. Mikkelson, K. Goodson, J. Santiago, and T. Kenny, "A Micromachined Low-Voltage Silicon Parallel-Plate Electrokinetic Pump," Proceedings of the $11^{\text {th }}$ International Conference on Solid-State Sensors and Actuators (Transducers 01 ), Munich, Germany (2001).

8. D.J. Laser, K.E. Goodson, J.G. Santiago, and T.W. Kenny, "Impact of Pumping Surface Separation Distance on Micromachined Silicon Electroosmotic Pump Performance," Proceedings of the 2001 ASME International Mechanical Engineering Congress and Exposition, New York, NY (2001).

9. C. Chen, S. Zeng, J. Mikkelsen, and J. Santiago, "Development of a Planar Electrokinetic Micropump," Proceedings of the 2000 ASME International Mechanical Engineering Congress and Exposition, Orlando, Florida (2000).

10. Polytec OFV 502 fiber interferometer with an OFV 3001 vibrometer controller, Polytec PI, Inc., Tustin, California.

${ }^{11}$ S. Yao, S. Zeng, and J.G. Santiago, "Transient Performance and Load-Change Response of Porous Glass Electroosmotic Pumps," submitted to the 2002 ASME International Mechanical Engineering Congress and Exposition, New Orleans, LA. 